\title{
THE CLINICAL PROFILE AND SEVERITY OF COMMUNITY ACQUIRED PNEUMONIA IN SPECIAL REFERENCE WITH PNEUMONIA SEVERITY INDEX
}

\author{
Jayaprasad Rajarajan'1, Daranendran Chellappa ${ }^{2}$
}

${ }^{1}$ Assistant Professor, Department of Medicine, Government Villupuram Medical College and Hospital, Tamilnadu.

${ }^{2}$ Assistant Professor, Department of Medicine, Government Villupuram Medical College and Hospital, Tamilnadu.

ABSTRACT
BACKGROUND
Community Acquired Pneumonia (CAP) is the infection of lung parenchyma in an individual who has not recently been
hospitalised. The mortality of CAP in hospitalised patients is $14 \%$ and those admitted in ICU increases to $20 \%-50 \%$. In developing
countries like India, an incidence of $20 \%-30 \%$ is reported as compared to $3 \%-4 \%$ in developed countries.
The objectives of the study are:
1) To know the clinical profile of the patients admitted with pneumonia in a tertiary care hospital.
2) To triage the patients and predict the outcome using pneumonia severity index (PSI).
3) To study the correlation between PSI and ICU admission, death and mortality at 30 days and followup.
4) To compare the results like age and sex distribution, outcomes, deaths etc. with similar studies.

\section{MATERIALS AND METHODS}

50 patients admitted in a tertiary care centre in south India with signs and symptoms of pneumonia were included in the study. After obtaining history and examination, the patients were subjected to relevant investigations. Patients were followed up for 30 days. For statistical analysis, the Chi-square test was used. The statistical significance was set at 0.05 level and the confidence interval at $95 \%$. The baseline parametric variables were expressed in percentages.

\section{RESULTS}

The common age group affected was between 40 to 65 years of age, of which males account for $62.5 \%$. Cough was the most common presenting symptom followed by difficulty in breathing, fever and chest pain. Culture and gram staining of sputum were positive in $30 \%$ and $50 \%$ respectively. Commonly associated comorbidities were heart failure and renal disease, diabetes mellitus being the commonest risk factor.

\section{CONCLUSION}

PSI (Pneumonia Severity Index) scoring correlates well with the mortality and morbidity at followup on the $30^{\text {th }}$ day. It was also effective in deciding whether the patient deserved ICU care.

\section{KEYWORDS}

Community Acquired Pneumonia, Pneumonia Severity Index.

HOW TO CITE THIS ARTICLE: Rajarajan J, Chellappa D. The clinical profile and severity of community acquired pneumonia in special reference with pneumonia severity index. J. Evolution Med. Dent. Sci. 2017;6(91):6480-6485, D0I: $10.14260 /$ jemds/2017/1408

\section{BACKGROUND}

The parenchymal infection of the lung is called pneumonia. Despite being the cause of significant morbidity and mortality, pneumonia is often misdiagnosed, mistreated and underestimated. Community Acquired Pneumonia (CAP) is the infection of lung parenchyma in an individual who has not recently been hospitalised. The mortality of CAP in hospitalised patients is $14 \%$ and those admitted in ICU increases to $20 \%$ - $50 \% .^{(1-3)}$

In developing countries like India, the incidence of about $20 \%-30 \%$ is reported as compared to $3 \%-4 \%$ incidence in developed countries.(4-6) The incidence varies markedly with age. Children upto 4 yrs. of age shows an incidence of

'Financial or Other Competing Interest': None.

Submission 04-10-2017, Peer Review 12-11-2017,

Acceptance 18-11-2017, Published 27-11-2017.

Corresponding Author:

Dr. Daranendran Chellappa,

Assistant Professor

Department of Medicine,

Government Villupuram Medical College,

Mundiyampakkam.

E-mail: daranendran@yahoo.com

DOI: $10.14260 / \mathrm{jemds} / 2017 / 1408$

$20 / 1000$ patients per year, after which it drops to $1-4 / 1000$ per year in young adults after $40 \mathrm{yrs}$. of age. It gradually rises to about $15-30 / 1000$ in $75-79$ yrs. of age and $40-60 / 1000$ in people over 85 yrs. of age.(7)

The cause of CAP is often difficult to establish even with the use of extensive lab investigations and invasive procedures, the aetiological confirmation being achieved in no more than $45 \%-70 \%$ of the patients with CAP. The aetiology of CAP remains uncertain in many patients.(8) Common causes are bacteria, viruses, fungi and parasites.

The clinical manifestations are cough, fever, difficulty in breathing and chest pain accompanied by constitutional symptoms. Specific signs of pulmonary consolidation are present only in $1 / 3^{\text {rd }}$ of the cases that need hospitalisation and less frequently in less ill patients. ${ }^{(9)}$

Severity assessment is one of the early steps in the management of CAP. There are currently 16 published prediction rules available, but most of these rules are not useful for triaging. Some of the commonly used scorings are-

1. Pneumonia Severity Index (PSI).

2. m-BTS (British Thoracic Society).

3. ATS (American Thoracic Society)- ICU admission criteria.

4. CURB- 65 etc. 


\section{The different outcomes that are to be studied are-}

1. Death.

2. Need for ICU care.

3. Duration of hospital stay.

4. Need for ventilator (or) inotropic support.

An early empirical therapy with routinely used antibiotics is usually effective while waiting for lab results.

The aim and objectives of the study are: 1) To know the clinical profile of the patients admitted with pneumonia in a tertiary care centre in south India; 2) To triage the patients and to predict the outcome using pneumonia severity index (PSI); 3) To study the correlation between PSI and ICU admission, death and mortality at 30 days and followup of the patients; 4) To compare the age and sex distribution, outcomes, deaths etc., with similar studies done before.

\section{MATERIALS AND METHODS}

\section{Setting}

Fifty patients of community acquired pneumonia, admitted in a tertiary care hospital, satisfying the inclusion and exclusion criteria were selected for the study. After obtaining history and examination, patients were subjected to relevant investigations.

\section{Inclusion Criteria}

Patients presenting with any opacity on chest radiograph associated with respiratory symptoms and signs suggestive of pneumonia were included in the study.

\section{Exclusion Criteria}

1. Patients $<12$ years of age.

2. Pregnant women.

3. HIV patients and sputum positive pulmonary TB patients.

4. Chronically immunosuppressed patients (solid organ transplanted patients, post-splenectomy patients).

5. Patients hospitalised within the previous 14 days for other illness.

6. Patients with an alternate diagnosis during followup.

\section{Study Design}

A clinical, prospective, observational study on community acquired pneumonia were admitted in our hospital.

\section{Study Protocol}

Fifty patients of community acquired pneumonia admitted in our hospital satisfying the inclusion criteria were included in the study. At the time of initial evaluation, the selected patients underwent a complete clinical history and examination, chest radiograph (posteroanterior view) at presentation, serum electrolytes, sputum for gram staining and culture, complete blood count, blood culture and Arterial Blood Gas analysis (in selected patients) were done.

Other investigations like pleural fluid analysis and bronchoalveolar lavage were done depending on the clinical scenario of the patients.

The pneumonia severity index was calculated for all the patients.

\begin{tabular}{|c|c|}
\hline Patient Characteristics & Points \\
\hline $\begin{array}{c}\text { Demographics } \\
\text { Age (years): Male: age } \\
\text { Female: age } \\
\text { Nursing home resident }\end{array}$ & $\begin{array}{l}\text { Age (yrs.) } \\
\text { Age (yrs.)-10 } \\
+10\end{array}$ \\
\hline $\begin{array}{c}\text { Co-morbidities } \\
\text { Neoplastic disease } \\
\text { Liver disease } \\
\text { Congestive heart failure } \\
\text { Cerebrovascular disease } \\
\text { Renal disease } \\
\end{array}$ & $\begin{array}{l}+30 \\
+20 \\
+10 \\
+10 \\
+10\end{array}$ \\
\hline $\begin{array}{c}\text { Physical Examination } \\
\text { Altered mental status } \\
\text { Respiratory rate }>30 / \text { min } \\
\text { Systolic blood pressure }<90 \\
\text { mmHg } \\
\text { Temperature }<35 \text { or }>40 \\
\text { degrees C } \\
\text { Pulse }>125 / \text { min }\end{array}$ & $\begin{array}{l}+20 \\
+20 \\
+20 \\
+15 \\
+10\end{array}$ \\
\hline $\begin{array}{c}\text { Lab and Radiologic } \\
\text { Findings } \\
\text { Arterial } \mathrm{pH}(\text { done only if } \\
\text { hypoxic) }<7.35 \\
\mathrm{BUN}>30 \mathrm{mg} / \mathrm{dL} \\
\text { Serum sodium }<130 \mathrm{mEq} / \mathrm{L} \\
\text { Glucose }>250 \mathrm{mg} / \mathrm{dL} \\
\mathrm{Haematocrit}<30 \% \\
\mathrm{PaO}_{2}<60 \mathrm{mmHg} \text { or } \mathrm{O}_{2} \\
\text { saturation }<90 \% \\
\text { Pleural effusion }\end{array}$ & $\begin{array}{l}+30 \\
+20 \\
+20 \\
+10 \\
+10 \\
+10 \\
+10\end{array}$ \\
\hline
\end{tabular}

At the Clinical Endpoint (Hospital Discharge or Death) the following Parameters were recorded-

1. Duration of hospital stay.

2. Time taken for defervescence.

3. Need for mechanical ventilation.

4. Need for admission to ICU.

5. Condition at 30 days after discharge from hospital.

In the present study, in hospital death (or) death within 30 days of discharge was the main outcome. Need for ICU admission was studied as a marker for severe pneumonia. Defervescence is defined as resolution of fever, chest pain, respiratory rate $\leq 24 / \mathrm{min}, \mathrm{SPO}_{2} \geq 90 \%$ on room air and ability to perform basic daily activities without support and also common presenting symptoms were observed.

A total number of 50 cases of pneumonia patients admitted at our hospital who met the inclusion criteria were studied.

\section{Statistical Analysis}

Statistical analysis was performed by Statistical Package for the Social Sciences (SPSS) version 20.0. The qualitative data were expressed as number (\%), while the continuous quantitative data as mean \pm standard deviation (SD) and the data was statistically analysed using Chi-square test. A pvalue of $<0.05$ was considered significant and at $<0.001$ was considered highly significant. 


\section{RESULTS}

\section{Age and Sex Distribution}

Out of 50 cases studied, 29 (58\%) cases were males and 21 $(42 \%)$ cases were females. The age ranged from 14 years to 80 years with a mean of $43.38 \pm 16.43$ years. The mean age of males (+SD) was $42.10 \pm 17.0$ and that of females was $45.14 \pm$ 15.93 (Higher for female by 3 years). The ratio of male:female was $1.38: 1$. The maximum incidence was seen in the age group of 40 - 65 years (48\%), of which $62.5 \%(15 / 24)$ of cases were males.

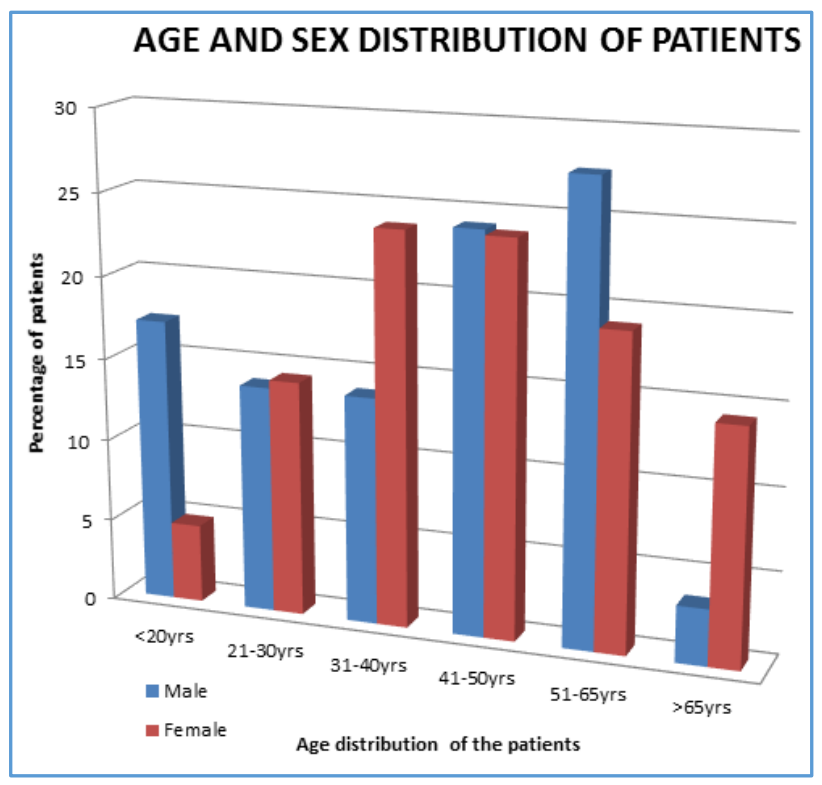

Figure 1. Age and Sex Distribution of Cases

\section{Presenting Symptoms}

Out of the 50 patients studied, the most common symptom was productive cough $96 \%(48 / 50)$ followed by difficulty in breathing accounting for $78 \%$ (39/50). The other symptoms were in the order of fever $76 \%(38 / 50)$, chest pain $74 \%$ (37/50) and 52\% (26/50), 40\% (20/50), 20\% (10/50) for headache, myalgia and haemoptysis respectively. Gastrointestinal symptoms like nausea and diarrhoea occurred in 38\% (19/50) and 8\% (4/50) respectively.

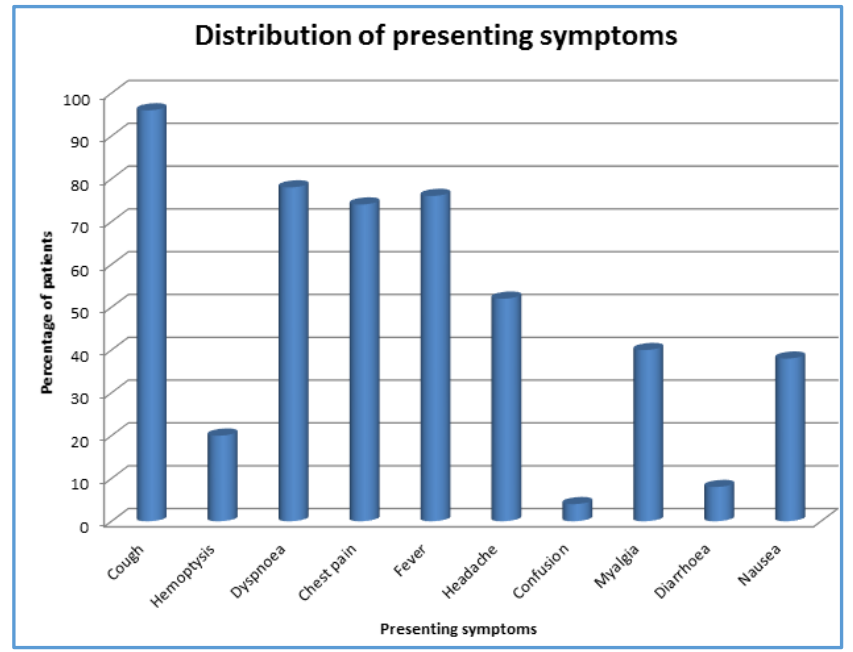

Figure 2. Symptoms at the Time of Presentation

\section{Associated Co-Morbidities}

In this study, the commonly associated co-morbidity was diabetes mellitus (10\%) followed by renal disease and heart failure, each accounting for $6 \%$. Malignancy co-existed with $4 \%$ of cases. COPD and liver disease were associated with $2 \%$ of cases each.

\section{X-Ray Chest}

In our study, upper lobe involvement was seen in 8\% (4) and the middle lobe involvement was seen in $24 \%$ (12) and the most commonly involved lobe was the lower lobe 36\% (18). Bilateral lesions occurred in 14\% (7) in the study group and pleural effusion occurred in $28 \%$ (14). Cavitary lesions were seen in $10 \%$ (5) of the patients. The right side was more commonly involved than the left.

\section{Microbial Testing}

In the present study, gram stain positivity was $50 \%$ and culture positivity was found to be $30 \%$.

\section{Complications of Pneumonia}

\begin{tabular}{|c|c|c|c|c|}
\hline Complications & Male & Female & Total & $\%$ \\
\hline Pleural effusion & 7 & 7 & 14 & $28 \%$ \\
\hline Empyema & 1 & 0 & 1 & $2 \%$ \\
\hline Lung abscess & 1 & 0 & 1 & $2 \%$ \\
\hline Respiratory failure & 2 & 1 & 3 & $6 \%$ \\
\hline ARDS & 1 & 0 & 1 & $2 \%$ \\
\hline Death & 0 & 1 & 1 & $2 \%$ \\
\hline Table 2. Sex Wise Distribution of Complications of \\
Pneumonia \\
\hline
\end{tabular}

In our study, pleural effusion was seen in $28 \%$ of the patients with pneumonia followed by respiratory failure in $6 \%$ of the patients. Other complications like empyema, lung abscess and ARDS occurred in $2 \%$ of the patients each. Death occurred in $2 \%$ of the patients.

\section{Organisms Recovered on Sputum Culture}

In our study, S. pneumoniae was recovered in $14 \%$ of the cases. P. aeruginosa and S. aureus were isolated from $6 \%$ and $4 \%$ respectively, K. pneumoniae and gram negative enteric bacilli from $4 \%$ and $2 \%$ of the patients respectively. Mixed and other infection constitute for $14 \%$ and $12 \%$ respectively.

In our study, renal and heart failure were the comorbidities associated with $6 \%$ of the patients followed by malignancy and liver disease constituting $4 \%$ and $2 \%$ respectively.

On physical examination, commonly occurring findings were an increased respiratory rate $(\geq 30 / \mathrm{min})$ in $18 \%$, followed by increased pulse rate ( $>125 / \mathrm{min})$ and confusion each contributing $4 \%$.

Among the lab findings increased urea was the commonest $(68 \%)$, followed by decreased haematocrit $(60 \%)$. The others were pleural effusion $(28 \%)$ and decreased saturation, decreased arterial $\mathrm{pH}$ and increased glucose seen in $4 \%$ each. 
Outcome of Pneumonia

In the present study $(49 / 50)$ recovered that is $98 \%$ and $2 \%$ died.
In our study, class 1 pneumonia was present in 15 patients (30\%). Class II and III pneumonia was seen in $22 \%$ and $24 \%$ respectively. It was $18 \%$ and $6 \%$ for class IV and V.

\section{PSI Scoring in Study Patients}

\section{Mortality}

In the present study, none of the patients belonging to class I, II, III, IV died of pneumonia. One out of 3 patients belonging to class-V died (33\%)

\section{Statistical Significance}

Statistical test used: Chi-square test.

\begin{tabular}{|c|c|c|c|c|c|c|}
\hline \multirow[b]{2}{*}{ Sl. No. } & \multirow[b]{2}{*}{ PSI Score } & \multicolumn{4}{|c|}{ OUTCOME } & \multirow{2}{*}{$\begin{array}{l}\text { Statistical } \\
\text { Inference }\end{array}$} \\
\hline & & Recovered $(n=48)$ & $\begin{array}{c}\text { Improved } \\
(n=1)\end{array}$ & Expired $(n=1)$ & $\begin{array}{c}\text { Total } \\
(n=50)\end{array}$ & \\
\hline 1 & Class I & $15(31.3 \%)$ & 0 & 0 & $15(30 \%)$ & \multirow{5}{*}{$\begin{array}{c}\mathrm{X}^{2}=20.602 \\
\mathrm{Df}=8 \\
0.008<0.05 \\
\text { Significant }\end{array}$} \\
\hline 2 & Class II & $11(22.9 \%)$ & 0 & 0 & $11(22 \%)$ & \\
\hline 3 & Class III & $12(25 \%)$ & 0 & 0 & $12(24 \%)$ & \\
\hline 4 & Class IV & $8(16.7 \%)$ & $1(100 \%)$ & 0 & $9(18 \%)$ & \\
\hline 5 & Class V & $2(4.2 \%)$ & 0 & $1(100 \%)$ & $3(6 \%)$ & \\
\hline
\end{tabular}

Statistical test: Chi-square test

The above table shows that there is a significant association between outcome of the respondents and their PSI score $(0.008<$ 0.05).

\begin{tabular}{|c|c|c|c|c|c|c|}
\hline \multirow[b]{2}{*}{ Sl. No. } & \multirow[b]{2}{*}{$\begin{array}{c}\text { Duration of } \\
\text { Hospital Stay }\end{array}$} & \multicolumn{4}{|c|}{ OUTCOME } & \multirow[b]{2}{*}{$\begin{array}{l}\text { Statistical } \\
\text { Inference }\end{array}$} \\
\hline & & Recovered $(n=48)$ & $\begin{array}{c}\text { Improved } \\
(n=1)\end{array}$ & Expired $(n=1)$ & $\begin{array}{c}\text { Total } \\
(n=50)\end{array}$ & \\
\hline 1 & Below 5 days & $12(25 \%)$ & 0 & $1(100 \%)$ & $13(26 \%)$ & \multirow{4}{*}{$\begin{array}{c}\mathrm{X}^{2}=27.364 \\
\mathrm{Df}=6 \\
0.000<0.05 \\
\text { Significant }\end{array}$} \\
\hline 2 & 6 to 10 days & $25(52.1 \%)$ & 0 & 0 & $25(50 \%)$ & \\
\hline 3 & 11 to 15 days & $10(20.8 \%)$ & 0 & 0 & $10(20 \%)$ & \\
\hline 4 & 16 days and above & $1(2.1 \%)$ & $1(100 \%)$ & 0 & $2(4 \%)$ & \\
\hline
\end{tabular}

Statistical test: Chi-square test

The above table shows that there is a significant association between outcome of the respondents and their duration of hospital stay $(.000<0.05)$.

\begin{tabular}{|c|c|c|c|c|c|c|c|c|c|}
\hline \multirow[b]{2}{*}{ Sl. No. } & \multirow[b]{2}{*}{ PSI Score } & \multicolumn{7}{|c|}{ Age } & \multirow{2}{*}{$\begin{array}{l}\text { Statistical } \\
\text { Inference }\end{array}$} \\
\hline & & $\begin{array}{l}\text { Below } 20 \\
\text { yrs. }(n=6)\end{array}$ & $\begin{array}{c}21 \text { to } 30 \\
\text { yrs. }(n=7)\end{array}$ & $\begin{array}{c}31 \text { to } 40 \\
\text { yrs. }(n=9)\end{array}$ & \begin{tabular}{|c|}
41 to 50 \\
yrs. $(n=12)$
\end{tabular} & $\begin{array}{c}51 \text { to } 60 \\
\text { yrs. }(n=8)\end{array}$ & $\begin{array}{c}61 \text { yrs. and } \\
\text { above }(n=8)\end{array}$ & $\begin{array}{c}\text { Total } \\
(n=50)\end{array}$ & \\
\hline 1 & Class I & $5(83.3 \%)$ & $4(57.1 \%)$ & $5(55.6 \%)$ & $1(8.3 \%)$ & 0 & 0 & $15(30 \%)$ & \multirow{5}{*}{$\begin{array}{c}\mathrm{X}^{2}=48.775 \\
\mathrm{Df}=20 \\
0.000<0.05 \\
\text { Significant }\end{array}$} \\
\hline 2 & Class II & $1(16.7 \%)$ & $2(28.6 \%)$ & $1(11.1 \%)$ & $7(58.3 \%)$ & 0 & 0 & $11(22 \%)$ & \\
\hline 3 & Class III & 0 & $1(14.3 \%)$ & $1(11.1 \%)$ & $2(16.7 \%)$ & $5(62.5 \%)$ & $3(37.5 \%)$ & $12(24 \%)$ & \\
\hline 4 & Class IV & 0 & 0 & $2(22.2 \%)$ & $1(8.3 \%)$ & $3(37.5 \%)$ & $3(37.5 \%)$ & $9(18 \%)$ & \\
\hline 5 & Class V & 0 & 0 & 0 & $1(8.3 \%)$ & 0 & $2(25 \%)$ & $3(6 \%)$ & \\
\hline
\end{tabular}

Statistical test: Chi-square test

The above table shows that there is a significant association between age of the respondents and their PSI score ratio $(.000<0.05)$.

Age is one of the important variables taken into account for calculating PSI scoring. The commonly involved age group in this study was 40 to 65 years of age. By using a statistical test called Chi-square test, it is noted that there is a significant association between the age and the PSI scoring with a p value of $0.000(<0.05)$. Gender also showed significant association between duration of hospital stay using the Chi-square test with $\mathrm{p}$ value of $0.064(<0.05)$. Thus, age and gender play important roles in deciding the class of PSI scoring and duration of hospital stay.
On testing the significance between outcome and PSI scoring, there is significant association between outcome and the PSI scoring with $\mathrm{p}$ value of $0.008(<0.05)$ and also significant correlation between outcome and the duration of hospital study with $\mathrm{p}$ value of $0.000(<0.05)$.

\section{DISCUSSION}

The observations made in 50 pneumonia patients at our hospital were discussed and compared with other similar studies.

\section{Age and Sex of the Patients}

In the present study of 50 patients, 29 (58\%) were males and $21(42 \%)$ were females with a mean age of $43.38 \pm 16.43$. The 
male: female ratio was 1.38: 1 and the maximum occurrence was seen in the age group of $40-65$ years - 48\% (24/50). Of these, males accounted for more cases of pneumonia, that is $62.5 \%(15 / 24)$. It is comparable with other studies like $\mathrm{S}$ Bansal et al,(10) Viraphong et al(11) and Bochud PY et al.(12) $S$ Bansal in his study on clinical and bacteriological profile of CAP in Shimla, Himachal Pradesh, reported that the mean age for the patients with CAP was $52.77 \pm 18.1$ and male-tofemale ratio was 2.4: 1.74 which was very much comparable with the present study.

Viraphong in South-East Asian J Trop Med Public health reported an average age of 49.5 and male: female ratio of 1:1.4. Bochud in the study of CAP, a prospective study stated that the average age was 43 . All the studies are comparable with the present study.

\begin{tabular}{|c|c|c|c|c|}
\hline $\begin{array}{c}\text { Study } \\
\text { Series }\end{array}$ & $\begin{array}{c}\text { Total No. of } \\
\text { Patients }\end{array}$ & $\begin{array}{c}\text { Males } \\
(\%)\end{array}$ & $\begin{array}{c}\text { Females } \\
(\%)\end{array}$ & $\begin{array}{c}\text { Male: } \\
\text { Female }\end{array}$ \\
\hline Bansal et al & 70 & 71.4 & 29.6 & $2.4: 1$ \\
\hline Present Study & 50 & 58 & 42 & $1.38: 1$ \\
\hline \multicolumn{5}{|c|}{ Table 6. Showing Age and Sex Comparison of } \\
various Studies \\
\hline
\end{tabular}

\section{Presenting Symptoms}

The presenting symptoms of the patients with CAP are compared with Bansal et al study. The most common presenting symptom in Bansal study was cough (97\%) and fever $(90 \%)$. In our study, cough and fever were seen in $96 \%$ and $76 \%$ respectively. Percentage of patients presenting with cough is almost the same as that of the previous study, but that of fever is $14 \%$ lesser.

Difficulty in breathing, pleuritic chest pain and haemoptysis were present in $48 \%, 34 \%$ and $14 \%$ respectively in the previous study. In the present study it accounted for $78 \%, 74 \%$ and $20 \%$ respectively, which is more than that of previous study by $30 \%, 40 \%$ and $6 \%$ respectively.

Altered sensorium was seen in $12 \%$ patients in Bansal et al study and in $4 \%$ of patients in the present study. Loose stools was complained by $10 \%$ of patients, which was almost comparable with the present study (8\%).

\begin{tabular}{|c|c|c|}
\hline $\begin{array}{l}\text { Presenting } \\
\text { Symptoms }\end{array}$ & $\begin{array}{c}\text { Bansal } \\
\text { et al (\%) }\end{array}$ & $\begin{array}{c}\text { Present } \\
\text { Study (\%) }\end{array}$ \\
\hline Cough & 97 & 96 \\
\hline Fever & 90 & 76 \\
\hline Dyspnoea & 48 & 78 \\
\hline Chest pain & 34 & 74 \\
\hline Haemoptysis & 14 & 20 \\
\hline Altered sensorium & 12 & 4 \\
\hline Diarrhoea & 10 & 8 \\
\hline
\end{tabular}

\section{Pattern of X-Ray Lesions}

The various patterns of $x$-ray findings in the present study were $36 \%$ involvement of lower zone and $24 \%$ of middle zone and pleural effusion in 28\%. In Bansal et al study too the commonly involved zone was the lower zone with $10 \%$ of cases showing pleural effusion, which was much lower than the present study.

\section{Gram Staining and Sputum Cultures}

In our study, the yield in gram staining and sputum cultures were $50 \%$ and $30 \%$ respectively. In many observational and retrospective studies of CAP, it was shown that an aetiological diagnosis had been established in less than $30 \%$ of hospitalised patients (Fine et al 1999; Lidman et al 2002).

\section{Complications of Pneumonia}

The various complications occurred to the patients in our study were pleural effusion (28\%), empyema (2\%) and respiratory failure (6\%), which is comparable to Bansal et al in which empyema was seen in $3 \%$ of cases and pleural effusion in $10 \%$ of cases.

\section{Organisms Recovered in Sputum Cultures}

The organisms that were recovered from cultures were $\mathrm{S}$. pneumoniae (14\%), mixed infections (14\%), P. aeruginosa (6\%), Klebsiella and S. aureus each (4\%) and Gram negative enteric bacilli (2\%), which was comparable to Maurico Ruitz et al study which showed $29 \%$ of S. pneumoniae, $23 \%$ of mixed infections, $6 \%$ of gram negative enteric bacilli and $5 \%$ of $P$. aeruginosa.

\section{Outcomes of Pneumonia}

In our study $98 \%$ recovered and $2 \%$ died since many patients were class I, II, III (76\%). So the mortality is low as compared with other studies.

\section{PSI Scoring in all Patients}

In our study $76 \%$ of cases were in class I, II and III. Class IV and $\mathrm{V}$ accounted for $18 \%$ and $6 \%$ respectively. One patient died in class $\mathrm{V}$ showing a mortality rate of $33 \%$ comparable to Fine et al study (29.2\%).

\section{PSI Scoring and Mortality}

In many studies, it is proved that PSI is a better predictor of mortality. In our study too, it is proved. Studies like that done by Aujesky D et al(13) did prospective comparison of three validated prediction rules for prognosis of CAP. It concluded that PSI had higher sensitivity and higher negative predictive value for mortality. Another study by Patel et al(14) comparing PSI and CURB in 2005 concluded that PSI is the good indicator for assessing the mortality in CAP.

\section{Limitations of PSI}

1. With 20 variables, it is too complex to use.

2. It oversimplifies certain variables.

3. Patients may have other reasons for admission as in case of our study, in which many patients fell in first 3 classes of PSI (76\%). Eg. Poor functional status, social support.

4. PSI is not applicable for certain cohorts.

\section{CONCLUSION}

Community acquired pneumonia is one of the commonest infections that we encounter in our day-to-day clinical practice, particularly in a developing country like India. It is also one of the leading causes of mortality and morbidity, particularly in the ICU setup.

In the present study, the commonly affected age group belongs to 40 - 65 years. But it can occur in any age group. There are many co-morbid conditions and risk factors, which 
increase the chance of getting CAP and also decides the severity of illness.

Even though there are many advanced investigations available, many a time it is difficult to arrive at an aetiological diagnosis. Since sensitivity and specificity for the presenting symptoms and the clinical examinations are low, it is necessary to depend on chest radiography and other investigations to diagnose a case of pneumonia.

The next step is to immediately start therapy for CAP, since it is proved in many studies that early initiation of therapy resulted in a better outcome. Many a time, empirical antibiotics to cover the possible organisms are used. There are many prediction rules available to triage the patient and to take a decision. Some will be better in predicting mortality like PSI and others will be useful to know the need for ICU care, etc.

To summarise, the conclusions of the study conducted at our hospital in a study population of 50 patients admitted with symptoms and signs suggestive of pneumonia are-

The commonly affected age group ranged from $40-65$ years (48\%), in which males accounted for $62.5 \%$. The age was $43.38+16.43$. The male-to-female ratio was 1.38: 1 .

The most common presenting symptom was cough (96\%) followed by difficulty in breathing, fever, chest pain and haemoptysis. On bacteriological examination, the results were positive for $50 \%$ of cases in gram staining and $30 \%$ in case of culture. The organisms recovered from culture were in the order of S. pneumoniae (14\%), mixed infections (14\%), P. aeruginosa (6\%), Klebsiella and S. aureus (4\%).

The co-morbidities commonly associated were heart failure and renal disease followed by malignancy and liver disease. Diabetes mellitus was also present in significant number of cases.

Most of the cases were treated with cephalosporins and fluoroquinolones. About $76 \%$ of the cases came under class I, II and III of PSI. Remaining 24\% were class IV (18) and V (6\%). The mortality correlated well with the PSI scoring.

To conclude, by using the knowledge of these criteria patients with CAP can be better prognosticated and triaged to utilise the resources and appropriate treatment so that we can improve the outcome in this disease.

\section{REFERENCES}

[1] Halm EA, Teirstein AS. Clinical practice: management of Community-acquired pneumonia. $\mathrm{N}$ Engl J Med 2002;347(25):2039-45.
[2] Fine MJ, Smith MA, Carson CA, et al. Prognosis and outcomes of patients with CAP: a meta-analysis. JAMA 1996;275(2):134-41.

[3] Torres A, Serra-Batlles J, Ferrer A, et al. Severe CAP. Epidemiology and prognostic factors. Am Rev Respir Dis 1991;144(2):312-8.

[4] Guidelines for management of CAP in adults admitted to hospital. The British Thoracic Society. Br J Hosp Med 1993;49(5):346-50.

[5] Karetzky M. Community Acquired Pneumonia. In: Brandstetter RD, Karetzky M, Cunhagu BA. eds. The Pneumonias. New York: Springers-Verlag 1993:25-48.

[6] Regional situation on health statistics and reporting. Health Situation in the SEAR 1994-1997. New Delhi: EHI/ WHO- SEARO. Sep 2007.

[7] Garibaldi RA. Epidemiology of Community Acquired Respiratory tract infections in adults: incidence, etiology and impact. Am J Med 1985;78(6B):32-7.

[8] Ishida T, Hashimoto T, Arita M, et al. Etiology of CAP in hospitalised patients: a 3 year prospective study in Japan. Chest 1998;114(6):1588-93.

[9] Lieberman D, Schlaeffer F, Boldur I, et al. Multiple pathogens in adult patients admitted with CAP: a one year prospective study of 346 consecutive patients. Thorax 1996;51(2):179-84.

[10] Bansal S, Kashyap S, Pal LS, et al. Clinical and bacterialogical profile of CAP in Shimla, Himachal Pradesh. Indian J Chest Dis Allied Sci 2004;46(1):1722.

[11] Wipa R, Viraphong L, Kittisak S, et al. The etiologies and treatment outcomes forout-patients with community-acquired pneumonia (CAP) at Srinagarind hospital, Khon Kaen, Thailand. South East Asian J Trop Med Public Health 2005;36(5):1262-7.

[12] Bochud PY, Moser F, Erard P, et al. Communityacquired pneumonia. A prospective outpatients study. Medicine (Baltimore) 2001;80(2):75-87.

[13] Aujesky D, Auble TE, Yealy DM, et al. Prospective comparison of three validated prediction rules for prognosis in CAP. Am J Med 2005;118(4):384-92.

[14] Patel AS. Lung alert. Comparing the Pneumonia Severity Index and CURB scores. Thorax 2005;60(9):722. 